\title{
Hubungan antara Tayangan Presiden Divaksin dengan Minat Vaksin Masyarakat
}

\author{
Ayu Arifah* \\ Prodi Public Relation, Fakultas Ilmu Komunikasi, Universitas Islam \\ Bandung, Indonesia. \\ *ayuarifah21@gmail.com
}

\begin{abstract}
The phenomenon of the increasingly widespread use of YouTube is certainly used by various parties for various purposes. In a pandemic situation like now, whether institutions, organizations, governments or media companies use YouTube as a medium to provide information and educate the public about things related to Covid-19. Kompas TV is one of the television stations that uses YouTube in disseminating information related to Covid-19. In the video entitled 'Be the First! President Joko Widodo is injected with the Sinovac Corona Vaccine. As of March 19, 2021, the video has been viewed 404,794 times. This shows that the public is enthusiastic about information regarding the injection of the Covid-19 vaccine. It can be seen from the significant difference between the number of video views and othe $\neg$ r video views regarding Covid-19 in the near future. In Bandung City, the percentage of confirmed cases continued to increase by $15.9 \%$ or higher than the national $7.74 \%$ and West Java Province 14.8\%. The continued increase in positive cases of Covid-19 is something that must be addressed immediately because the Covid-19 pandemic, which has been running since December 2019, has not improved. In addition to implementing health protocols, vaccines are one way to prevent and break the chain of the spread of Covid-19 so that it does not spread further. Therefore, the researcher was interested in conducting a study entitled "The Relationship Between Impressions of the President being vaccinated and Interest in Vaccination in the City of Bandung". The purpose of this study was to determine the relationship between the president's youtube impressions being vaccinated with the public's interest in vaccines in the city of Bandung. The method used is correlational quantitative. Data collection techniques were carried out by distributing questionnaires to 96 people from Dago Village, Bandung City. The analysis technique used is descriptive analysis. The results of this study are that there is a strong relationship between the president's youtube impressions being vaccinated with the public's interest in vaccines.
\end{abstract}

Keywords: Views, Youtube, Duration, Frequency, Interests

Abstrak. Fenomena penggunaan YouTube yang semakin merebak tentunya dimanfaatkan oleh berbagai pihak untuk berbagai tujuan. Di situasi pandemi seperti sekarang, baik lembaga, organisasi, pemerintah atau perusahaan media menggunakan youtube sebagai salah satu media untuk memberikan informasi dan mengedukasi masyarakat mengenai hal-hal yang berkaitan dengan Covid19. Kompas TV menjadi salah satu stasiun televisi yang menggunakan YouTube dalam menyebarkan informasi yang berkaitan dengan Covid-19. Pada video yang berjudul 'Jadi yang Pertama! Presiden Joko Widodo Disuntik Vaksin Corona Sinovac'. Hingga 19 Maret 2021, video tersebut telah ditonton sebanyak 404.794 kali. Hal tersebut menunjukkan bahwa masyarakat antusias akan informasi mengenai penyuntikan vaksin Covid-19. Terlihat dari perbedaan yang signifikan antara jumlah views video tersebut dengan views video mengenai Covid-19 lainnya dalam kurun waktu yang berdekatan. Di Kota Bandung, persentase kasus konfirmasi terus mengalami kenaikan sebesar 15,9\% atau lebih tinggi dibandingkan nasional 7,74\% dan Provinsi Jabar 14,8\%. Terus melonjaknya kasus positif Covid-19 ini menjadi hal yang harus segera ditangani karena pandemi Covid-19 yang sudah berjalan sejak Desember 2019 lalu ini tidak kunjung membaik. Selain dengan menerapkan protokol kesehatan, vaksin menjadi salah satu cara untuk mencegah dan memutus rantai penyebaran Covid-19 agar tidak semakin meluas. Maka dari itu, peneliti merasa tertarik untuk melakukan penelitian yang berjudul "'Hubungan Antara Tayangan Presiden Divaksin Dengan Minat Vaksin Masyarakat Di Kota Bandung". Tujuan penelitian ini adalah untuk mengetahui sejauh mana hubungan tayangan youtube presiden divaksin dengan minat vaksin masyarakat di Kota Bandung. Metode yang digunakan adalah kuantitatif korelasional. Teknik pengumpulan data dilakukan dengan menyebarkan kuesioner kepada 96 orang masyarakat Kelurahan Dago, Kota Bandung. Teknik analisis yang digunakan adalah analisis deskriptif. Hasil penelitian ini adalah terdapat hubungan positif antara tayangan youtube "Jadi yang Pertama! Presiden Joko Widodo Disuntik Vaksin Corona Sinovac" dengan minat vaksin masyarakat yang termasuk kategori kuat. Hal ini berarti bahwa tayangan youtube presiden divaksin tersebut dapat memunculkan minat dalam diri masyarakat Kelurahan Dago.

Kata Kunci: Tayangan, Youtube, Durasi, Frekuensi, Minat 


\section{A. Pendahuluan}

Media massa termasuk salah satu bentuk kemajuan teknologi bidang informasi dan komunikasi. Keberadaannya kini menjadi sebuah kebutuhan masyarakat dari semua lapisan masyarakat. Dengan bantuan media massa, penyampaian informasi untuk khalayak menjadi semakin mudah. Tingginya minat masyarakat terhadap komunikasi melalui media massa seperti film, radio, surat kabar, televisi dan internet membuat masyarakat dan media massa tidak dapat dipisahkan.

Hampir semua orang mengakses media massa dengan bantuan internet. Youtube menjadi salah satu media sosial yang paling populer di kalangan masyarakat saat ini. Melalui youtube, kita bisa mendapatkan referensi semua konten yang kita butuhkan. Youtube tidak hanya berisi video musik, film dan hiburan, tetapi juga memiliki kekayaan pengetahuan, seperti video tutorial memasak, editing foto atau film, bermain musik hingga bidang-bidang khusus seperti teknologi informasi.

Dikutip dari kompas.com, riset terbaru yang dilakukan perusahaan aplikasi manajemen media sosial Hootsuite dan agensi marketing We Are Social menunjukkan hasil bahwa, "Youtube adalah media sosial yang paling sering dipakai selama satu bulan. Sebanyak 93,8\% dari jumlah seluruh pengguna internet di Indonesia dengan kisaran usia 16-64 tahun menggunakan youtube dengan durasi rata-rata berkisar 25,9 jam per bulan'.

Fenomena penggunaan YouTube yang semakin menjamur tentunya dimanfaatkan oleh berbagai pihak untuk berbagai tujuan. Di situasi pandemi seperti sekarang, baik lembaga, organisasi, pemerintah atau perusahaan media menggunakan youtube untuk menyampaikan informasi dan mengedukasi masyarakat mengenai hal-hal seputar Covid-19.

Kompas TV menjadi salah satu stasiun televisi yang menggunakan YouTube untuk menyebarkan informasi yang berkaitan dengan Covid-19. Salah satu video yang diunggah di youtube Kompas TV adalah mengenai pemberitaan vaksin Covid-19. 13 Januari 2021, Kompas TV menggunggah sebuah video yang berjudul 'Jadi yang Pertama! Presiden Joko Widodo Disuntik Vaksin Corona Sinovac'. Hingga saat ini, 19 Maret 2021, video tersebut telah ditonton sebanyak 404.794 kali. Hal tersebut menunjukkan antusias masyarakat terhadap informasi seputar vaksin Covid-19.

Sejak kemunculan kasus pertama corona di dunia pada Desember tahun 2019 lalu, jumlah pasien positif Covid-19 terus naik. Dilansir dari jabar.inews.com, di Kota Bandung sendiri persentase kasus konfirmasi terus mengalami kenaikan sebesar 15,9\% atau lebih tinggi dibandingkan nasional 7,74\% dan Provinsi Jabar 14,8\%. Data tersebut menunjukkan penularan Covid-19 masih tinggi dan menjadikan Kota Bandung masuk ke dalam zona resiko sedang.

Kelurahan Dago ialah salah satu kelurahan di Kecamatan Coblong dan menjadi kelurahan dengan total kasus aktif Covid-19 paling banyak dengan 239 kasus per 21 Maret 2021. Dalam lingkup Kota Bandung, Kelurahan Dago juga menjadi kelurahan dengan kasus aktif Covid-19 terbanyak kedua setelah Kelurahan Antapani Kidul.

Selain dengan menerapkan protokol kesehatan, vaksin menjadi salah satu cara untuk mencegah dan memutus rantai penyebaran Covid-19 agar tidak semakin meluas. Namun program vaksinasi yang ditawarkan pemerintah ini menimbulkan beragam reaksi di kalangan masyarakat, ada yang menyambut dengan senang hati, ada yang meragukan keefektifannya dan ada juga yang menentangnya secara terang-terangan. Hal ini dilatar belakangi oleh merebaknya hoax di kalangan masyarakat mengenai vaksin sinovac yang akan digunakan di Indonesia.

Dilansir dari kompas.com, Jubir Kementerian Komunikasi Informatika, Dedy Permadi menjelaskan, hingga 10 Februari 2021 telah ditemukan 105 isu hoaks berkenaan vaksin Covid19 di berbagai platform media sosial seperti Instagram, Facebook, Twitter, Youtube hingga TikTok.

Oleh karena itu, peneliti tertarik untuk melakukan penelitian dengan judul ' Hubungan Antara Tayangan Presiden Divaksin dengan Minat Vaksin Masyarakat Di Kota Bandung'” pada masyarakat Kelurahan Dago, Kota Bandung.

Berdasarkan latar belakang yang telah diuraikan, maka perumusan masalah dalam penelitian ini sebagai berikut:

“Apakah Terdapat Hubungan Antara Tayangan Youtube 'Jadi yang Pertama! Presiden 
Joko Widodo Disuntik Vaksin Corona Sinovac' dengan Minat Vaksin Masyarakat di Kota Bandung?"'.

Selanjutnya, tujuan dalam penelitian ini diuraikan dalam pokok-pokok sbb.

1. Untuk menguji hubungan antara durasi tayangan youtube 'Jadi Yang Pertama! Presiden Joko Widodo Disuntik Vaksin Corona Sinovac' dengan minat vaksin masyarakat di Kota Bandung.

2. Untuk menguji hubungan antara frekuensi tayangan youtube 'Jadi Yang Pertama! Presiden Joko Widodo Disuntik Vaksin Corona Sinovac' dengan minat vaksin masyarakat di Kota Bandung.

\section{B. Metodologi Penelitian}

Penelitian ini merupakan penelitian kuantitatif dengan pendekatan studi korelasioanal. Pendekatan korelasional digunakan untuk mengetahui hubungan antara variabel yang akan diuji dimana kita dapat mendeskripsikan juga memperkirakan hubungan antar variabel. Selain mengetahui besarnya kontribusi variabel independent terhadap variabel dependen, peneliti juga dapat mengetahui besarnya arah hubungan antar variabel tersebut.

Populasi dalam penelitian ini adalah masyarakat Kelurahan Dago, Kota Bandung dengan rentang usia 20-24 tahun yang berjumlah 2.269 orang. Dari populasi tersebut diambil sampel dengan menggunakan teknik non probability sampling; accidental sampling. Teknik tersebut memungkinkan peneliti untuk mengambil sampel secara accidental dengan mengambil responden yang kebetulan ada disuatu tempat yang sesuai dengan tempat penelitian (Notoatmodjo, 2010).

Dengan menggunakan rumus slovin, didapat jumlah sampel dalam penelitian ini yaitu 96 responden. Teknik pengumpulan data dilakukan dengan menyebarkan angket atau kuesioner berbentuk google form melalui media sosial seperti grup line, grup whatsapp, dan Instagram. Selain itu, tambahan data diambil dari studi kepustakaan. Adapun teknik analisis data dilakukan dengan analisis deskriptif dan uji statistik

\section{Hasil Penelitian dan Pembahasan}

Dalam analisis inferensial data ini akan membahas pengujian hipotesis apakah terdapat hubungan antara tayangan presiden divaksin dengan minat vaksin masyarakat. Pengujian ini dilakukan dengan cara analisis korelasi bivariat yang ditujukan untuk mengetahui keeratan hubungan antara Tayangan Youtube sebagai variabel independent pada Minat sebagai variabel dependent.

Pada penelitian ini, terdapat satu hipotesis utama yang diajukan. Berikut ini adalah hasil uji mengenai hubungan antara tayangan presiden divaksin dengan minat vaksin masyarakat di Kelurahan Dago, yang akan dijelaskan sebagai berikut:

1. H0 ditolak jika nilai signifikasi $<0.05$

2. H0 diterima jika nilai signifikasi $>0.05$

Langkah selanjutnya yaitu memperhatikan angka koefisien korelasi. Jika nilai korelasi $=-1$ maka korelasinya negatif sempurna. Jika koefisien korelasi $=0$ maka tidak ada korelasi. Dan jika angka koefisien korelasinya $=1$ maka korelasinya sangat kuat. Berikut tabel arti harga koefisien korelasi:

Tabel 1. Tabel Tingkat Asosiasi

\begin{tabular}{|c|c|}
\hline Nilai Mutlak Ukuran Asosiasi & Tingkat Hubungan \\
\hline .000 & Tidak Ada Hubungan \\
\hline $.001-.199$ & Lemah \\
\hline $.200-.399$ & Sedang \\
\hline $.400-.599$ & Kuat \\
\hline
\end{tabular}




\begin{tabular}{|c|c|}
\hline $.600-.999$ & Sangat Kuat \\
\hline 1.000 & Hubungan Sempurna \\
\hline
\end{tabular}

Sumber: Rakhmat dan Ibrahim, (2019: 161)

Hubungan Tayangan Youtube (X) dengan Minat Vaksin Masyarakat (Y)

Berikut adalah penelitian mengenai hubungan antara Hubungan Tayangan Youtube dengan Minat Vaksin Masyarakat, yang diuji menggunakan teknik analisis korelasi Rank Spearman. Hasil pengujian dijelaskan pada tabel 1.

Tabel 2. Hubungan Antara Tayangan Youtube (X) Dengan Minat Vaksin Masyarakat (Y)

\begin{tabular}{|c|c|c|c|c|c|}
\hline Korelasi & \multicolumn{3}{|c|}{ Variabel Minat (Y) } & \multirow{2}{*}{$\begin{array}{l}\text { Tingka } \\
\text { t } \\
\text { Hubun } \\
\text { gan }\end{array}$} & \multirow[b]{2}{*}{ Ket. } \\
\hline Variabel $(\mathbf{X})$ & $\begin{array}{l}\text { Correlation } \\
\text { Coefficients }\end{array}$ & $\begin{array}{l}\text { Sig. (2- } \\
\text { tailed) }\end{array}$ & $\begin{array}{l}\text { Cut-off } \\
\text { Value }\end{array}$ & & \\
\hline $\begin{array}{c}\text { Terpaan Media } \\
\text { (Tayangan Youtube) }\end{array}$ & 0,435 & 0,000 & 0,05 & $\begin{array}{l}\text { Tingka } \\
\mathrm{t} \\
\text { Hubun } \\
\text { gan } \\
\text { Kuat }\end{array}$ & $\begin{array}{c}\mathrm{H} 1 \\
\text { diteri } \\
\text { ma }\end{array}$ \\
\hline
\end{tabular}

Sumber: Data Penelitian yang Sudah Diolah, 2021.

Dari tabel di atas, hasil pengujian kolerasi bivariat dari hipotesis utama yang diujikan yaitu variabel Tayangan Youtube dan Minat. Dari tabel tersebut, terlihat bahwa nilai koefisien korelasi yang menunjukkan bahwa hubungan antara variabel Tayangan Youtube dan Minat adalah sebesar 0,435. Angka tersebut berada diantara 0,400 - 0,599 yang berarti bahwa kedua variabel tersebut memiliki hubungan yang kuat dan positif.

Selain itu, sebagai pengujian hipotesis tabel di atas menunjukkan nilai signifikansi antara variabel Tayangan Youtube sebagai variabel independen secara keseluruhan dengan variabel dependennya yaitu Minat adalah sebesar 0,000 yang mana nilai tersebut menunjukkan angka lebih kecil dari nilai kritis yaitu 0,05 . Hal tersebut berarti bahwa variabel Tayangan Youtube secara langsung memiliki kolerasi atau hubungan yang nyata dan signifikan terhadap variabel Minat. Maka dari itu, pengujian tersebut menunjukkan bahwa H0 ditolak dan H1 diterima.

H1 : Ada hubungan antara tayangan youtube 'Jadi Yang Pertama! Presiden Joko Widodo Disuntik Vaksin Corona Sinovac' dengan minat vaksin masyarakat di Kelurahan Dago, Kota Bandung

\section{Hubungan Durasi Tayangan Youtube (X1) dengan Minat Vaksin Masyarakat (Y)}

Tabel 3. Hubungan Antara Durasi (X1) Dengan Minat Vaksin Masyarakat (Y)

\begin{tabular}{|c|c|c|c|c|c|}
\hline Korelasi & \multicolumn{3}{|c|}{ Variabel Minat (Y) } & \multirow{2}{*}{$\begin{array}{l}\text { Tingkat } \\
\text { Hubung } \\
\text { an }\end{array}$} & \multirow[b]{2}{*}{ Ket. } \\
\hline $\begin{array}{c}\text { Variabel } \\
(\mathrm{X} 1)\end{array}$ & $\begin{array}{l}\text { Correlation } \\
\text { Coefficients } \\
\end{array}$ & $\begin{array}{l}\text { Sig. (2- } \\
\text { tailed) }\end{array}$ & $\begin{array}{c}\text { Cut-off } \\
\text { Value }\end{array}$ & & \\
\hline Durasi & 0,829 & 0,000 & 0,05 & $\begin{array}{l}\text { Tingkat } \\
\text { Hubunga } \\
\text { n Sangat } \\
\text { Kuat }\end{array}$ & $\begin{array}{c}\mathrm{H} 1 \\
\text { diteri } \\
\text { ma }\end{array}$ \\
\hline
\end{tabular}

Sumber: Data Penelitian yang Sudah Diolah, 2021

Dari tabel di atas, hasil pengujian antara hubungan dimensi durasi tayangan youtube dengan variabel minat menunjukkan hasil nilai koefisien korelasi dengan angka 0,829 yang berada diantara 0,600 - 0,999. Angka tersebut dapat diartikan bahwa dimensi durasi tayangan 
youtube memiliki tingkat hubungan yang sangat kuat dengan variabel minat.

Selanjutnya, terdapat juga pengujian hipotesis yang ditunjukkan dengan nilai signifikansi yaitu sebesar 0,000 yang mana lebih kecil dari nilai kritis 0,05 . Hal tersebut menunjukkan bahwa dimensi durasi tayangan youtube ini memiliki hubungan yang signifikan dan positif dengan variabel minat. Maka dari itu, H1 diterima.

\section{Hubungan Frekuensi Tayangan Youtube (X2) dengan Minat Vaksin Masyarakat (Y)}

Tabel 4. Hubungan Antara Frekuensi (X2) Dengan Minat Vaksin Masyarakat (Y)

\begin{tabular}{|c|c|c|c|c|c|}
\hline Korelasi & \multicolumn{3}{|c|}{ Variabel Minat (Y) } & \multirow{2}{*}{$\begin{array}{l}\text { Tingkat } \\
\text { Hubung } \\
\text { an }\end{array}$} & \multirow[b]{2}{*}{ Ket. } \\
\hline $\begin{array}{c}\text { Variabel } \\
\text { (X2) }\end{array}$ & $\begin{array}{l}\text { Correlation } \\
\text { Coefficients }\end{array}$ & $\begin{array}{l}\text { Sig. (2- } \\
\text { tailed) }\end{array}$ & $\begin{array}{c}\text { Cut-off } \\
\text { Value }\end{array}$ & & \\
\hline Frekuensi & 0,801 & 0,000 & 0,05 & $\begin{array}{l}\text { Tingkat } \\
\text { Hubunga } \\
\text { n Sangat } \\
\text { Kuat }\end{array}$ & $\begin{array}{c}\text { H1 } \\
\text { diteri } \\
\text { ma }\end{array}$ \\
\hline
\end{tabular}

Sumber: Data Penelitian yang Sudah Diolah, 2021

Dari tabel di atas, hasil pengujian antara hubungan dimensi frekuensi tayangan youtube dengan variabel minat menunjukkan hasil nilai koefisien korelasi sebesar 0,801 yang berada diantara 0,600 - 0,999. Angka tersebut dapat diartikan bahwa frekuensi tayangan youtube memiliki tingkat hubungan yang sangat kuat dan positif dengan variabel minat.

Selanjutnya, terdapat juga hasil pengujian hipotesis yang ditunjukkan dengan nilai signifikansi yaitu sebesar 0,000 yang mana lebih kecil dari nilai kritis 0,05. Hal tersebut menunjukkan bahwa frekuensi tayangan youtube ini memiliki hubungan yang signifikan dengan variabel minat. Dengan begitu sub hipotesis kedua yang diterima adalah H1.

Tayangan Youtube dalam penelitian ini meliputi durasi dan frekuensi. Sedangkan minat meliputi perasaan senang, perhatian, ketertarikan, dan keterlibatan.

Hasil dari penelitian terlihat bahwa setelah responden menonton tayangan youtube 'Jadi yang Pertama! Presiden Joko Widodo Disuntik Vaksin Corona Sinovac', dapat memunculkan minat vaksin di masyarakat. Hal ini disebabkan karena pada saat menonton tayangan tersebut, responden terkena terpaan media yaitu banyaknya informasi yang diperoleh dari penggunaan media yang meliputi frekuensi, atensi, dan durasi penggunaan media (Rakhmat, 2004: 66).

Semakin lama seseorang terkena terpaan media tentu saja semakin besar juga efek yang dirasakan entah dalam bentuk perubahan pengetahuan, perasaan, sikap atau perilaku. Seperti yang dijelaskan Winarni (2003: 100), bila ditinjau dari segi isi pesan, ada tiga efek yang ditimbulkan, yaitu:

1. Efek Kognitif, Akibat yang timbul pada diri individu karena terkena terpaan media yang sifatnya informatif bagi dirinya. yang awalnya tidak tahu menjadi tahu, tidak jelas menjadi jelas, ragu menjadi yakin, dan sebagainya. Artinya, dengan melalui media, khalayak akan memperoleh gambaran atau informasi tentang orang, benda, peristiwa atau kejadian, tempat - tempat yang belum pernah di kunjungi.

2. Efek Afektif, Efek ini kadarnya lebih tinggi dibandingkan efek kognitif, dikarenakan efek yang di timbulkan mengacu pada aspek emosional. Jadi tidak hanya sekedar menjadi tahu tentang sesuatu yang baru melainkan khalayak juga dapat merasakannya.

3. Efek Behavioral, Efek yang mengacu pada perilaku, tindakan atau kegiatan khalayak yang tampak pada kegiatan sehari - hari.

Ditambah lagi, tayangan youtube presiden divaksin tersebut adalah salah satu bentuk kampanye yang disebut ideological or cause campaign yang orientasi tujuannya bersifat khusus dan berdimensi sosial. Dalam hal ini, tujuan dari kampanye melalui tayangan youtube presiden divaksin tersebut adalah untuk meningkatkan awareness dan partisipasi masyarakat mengenai vaksin covid-19. Selain itu, dengan adanya tayangan youtube presiden divaksin juga menjadi bukti bahwa program vaksin covid-19 ini juga terjamin aman untuk digunakan oleh masyarakat. 


\section{Kesimpulan}

Berdasarkan pembahasan dalam penelitian ini, peneliti menyimpulkan beberapa hasil penelitian yaitu terdapat hubungan positif antara tayangan youtube "Jadi yang Pertama! Presiden Joko Widodo Disuntik Vaksin Corona Sinovac" dengan minat vaksin masyarakat yang termasuk kategori kuat. Hal ini berarti bahwa tayangan youtube presiden divaksin tersebut dapat memunculkan minat dalam diri masyarakat Kelurahan Dago karena efek dari terpaan media itu sendiri. Selain itu, pengalaman merasakan pandemic sejak tahun 2020 lalu, memunculkan adanya perhatian, ketertarikan dan keinginan untuk ikut terlibat dalam kegiatan vaksin Covid19.

Terdapat hubungan positif antara durasi tayangan youtube "Jadi yang Pertama! Presiden Joko Widodo Disuntik Vaksin Corona Sinovac" dengan minat vaksin masyarakat yang termasuk kategori sangat kuat. Hal ini berarti bahwa tayangan youtube presiden divaksin tersebut dapat memunculkan minat dalam diri masyarakat Kelurahan Dago karena semakin lama seseorang mengkonsumsi suatu media, semakin banyak pula informasi yang akan didapat dan tentunya hal tersebut dapat mempengaruhi perilaku. Dalam hal ini, mayoritas masyarakat Kelurahan Dago menyatakan bahwa memiliki keinginan untuk divaksin setelah menonton tayangan youtube tersebut.

Terdapat hubungan positif antara frekuensi tayangan youtube "Jadi yang Pertama! Presiden Joko Widodo Disuntik Vaksin Corona Sinovac' dengan minat vaksin masyarakat yang termasuk kategori sangat kuat. Hal ini berarti bahwa tayangan youtube presiden divaksin tersebut dapat memunculkan minat dalam diri masyarakat Kelurahan Dago karena semakin sering seseorang mengkonsumsi suatu media, semakin banyak pula informasi yang akan didapat dan tentunya hal tersebut dapat mempengaruhi perilaku. Dalam hal ini, mayoritas masyarakat Kelurahan Dago menyatakan bahwa memiliki keinginan untuk divaksin setelah menonton tayangan youtube tersebut.

\section{Acknowledge}

Peneliti ingin mengucapkan terima kasih kepada Prof. Neni Yulianita., Dra., M.Si. sebagai dosen pembimbing karena atas bimbingannya peneliti dapat menyelesaikan penelitian ini. Tak lupa juga terima kasih kepada seluruh responden yang telah membantu peneliti sehingga penelitian ini dapat berjalan lancar dan selesai tepat waktu.

\section{Daftar Pustaka}

[1] Clinten, Bill. 2021. 'Pengguna Medsos di Indonesia Habiskan 25 Jam Per Bulan untuk Nonton YouTube', https://tekno.kompas.com/read/2021/02/24/17020027/penggunamedsos-di-indonesia-habiskan-25-jam-per-bulan-untuk-nonton-youtube. Tanggal akses 19 Maret 2021, pk. 11.35 WIB.

[2] Warsudi, Agus. 2021. 'Kota Bandung Zona Oranye, Penyebaran Covid-19 Masih Tinggi',, https://jabar.inews.id/berita/kota-bandung-zona-oranye-penyebaran-covid-19-masih-tinggi. Tanggal akses pada 22 Maret 2021, pk. 16.00 WIB.

[3] Winarni. 2003. Komunikasi Massa Suatu Pengantar. Malang: Universitas Muhammadiyah Malang.

[4] Rakhmat, Jalaluddin, 2004. Metode Penelitian Komunikasi: Dilengkapi Contoh Analisis Statistik. Bandung: PT Remaja Rosdakarya.

[5] Rakhmat, Jalaluddin. 2019. Metode Penelitian Komunikasi. Bandung: PT. Remaja Rosdakarya

[6] Notoatmodjo, S. 2010. Metodologi Penelitian Kesehatan. Jakarta : Rineka Cipta.

[7] Sari, Haryanti Puspa. 10 Februari 2021. Kemenkominfo Temukan 105 Isu Hoaks Terkait Vaksin Covid-19. https://nasional.kompas.com/read/2021/02/10/19545431/kemenkominfotemukan-105-isu-hoaks-terkait-vaksin-covid-19, diakses pada 15 Maret 2021 pukul 17.32 WIB. 